\title{
Quantitative Microscopic evaluation of Melatonin treatment of Experimentally Atherosclerotic Rabbit Aorta
}

\author{
Mattar FE *; Ismael AA*; Kassem M.A **;Sharaf, H.A. and Ibrahim IK** \\ From the Department of Histology, Al-Azhar Faculty of Medicine in Cairo* , in Assiut \\ ** and Pathology Dept. National Research Center, Dokki-Giza
}

\begin{abstract}
Atherosclerosis is one of the most common diseases in Egypt. The exact etiology of the disease is still vague. However, Oxidative modifications of low-density lipoprotein (LDL) have been proposed to play a critical role in atherogenesis. Antioxidants have been proposed, therefore, to have a possible role in protection and/or prevention of atherosclerosis. The pineal gland hormone, melatonin, have been reported as an antioxidant. Recently melatonin has been proposed to interfere with one of the chain of events in the onset of atherosclerosis, that is, the formation of adhesion molecules. To test the role of melatonin in amelioration of atherogenesis, this work was designed to study the atherosclerosis-.related microscopic changes in the aorta of melatonin treated, high cholesterol fed rabbits.

Thirty adult male rabbits were used throughout this work. The animals were fed a standard rabbit food free from cholesterol and antioxidants. The rabbits were divided into three groups each of 10 animals: Control (A) group, was raised on the ordinary diet alone for 6 weeks. Atherosclerotic induced, non treated (B) group was raised on the ordinary diet mixed with $1 \%$ cholesterol powder for a period of 6 weeks. Atherosclerotic induced, melatonin treated (C) group was raised on the ordinary diet mixed with $1 \%$ cholesterol powder and drenched $4.2 \mathrm{mg}$ melatonin dissolved in saline solution daily at night for 6 weeks. The drug was given through naso-gastric tube under light ether anesthesia

Paraffin sections of both control and experimental groups were prepared on the same slide. The sections were stained by haematoxylin and eosin, Masson trichrome, orcein; or periodic acid Schiff (PAS).

The endothelial thickness, relative collagen, elastic fibers, smooth muscle fibers and glycosaminoglycan content in control and experimental groups were evaluated by computerized image analyzer. Statistical analysis of the results was carried out using Microsoft Excel 2000.

The results revealed that the melatonin has antiatherosclerotic effects in experimental atherosclerosis in the rabbit aorta. Melatonin significantly reduced specific atherosclerotic lesions like fibrosis, smooth muscle atrophy, and decreased elastic fiber content in thoracic aortic wall.

In conclusion, melatonin may be of value in the management of atherosclerosis by reducing its complications.
\end{abstract}

\section{Introduction}

Atherosclerosis is one of the common diseases among middle age and old age Egyptians. The exact etiology of the disease is still indefinite. In atherosclerosis, fatty material accumulates in the intima with additional fibrosis. This material is covered by dense fibrous tissue, which gives the plaque a white, pearly appearance (Walter $\&$ Israel, 1990). These features result in the hardening of the arterial wall due to thicke ning and loss of elasticity (Cormack , 1997). Hemorrhage, thrombosis, ulceration and calcification are advanced and late complicated lesions of atherosclerosis 
(Walter \& Israel, 1990).

Atherosclerosis is potentially a life threatening disease in which either elastic or muscular arteries develop characteristic lesions known as atheromatous (atherosc lerotic) plaques. Widely viewed as a multistaged, interactive tissue response to focal damage of the arterial endothelium, this condition appears to result from minor local disruption of the intimal endothelial cell barrier of arteries. Such disruption can elicit an extended series of events that include (Cormack, 1997): Focal adhesion and subendothelial invasion of monocytes that transform into macrophages and accumulate lipids. Migration of smooth muscle cells from the media into the intima of the affected site.

Intense growth factor-induced prolif erative responses by the smooth muscle cells that have migrated to the intima.

Deposition of low density lipoproteinderived cholesterol in proliferated smooth muscle cells, in macrophages that have accumulated in the intima, and also in the newly produced interstitial matrix of the intima itself.

A theory known as modified lipop rotein theory (Steinberg, 1983), suggests that at an early stage of diet induced athero -sclerotic plaques, the endothelium " pumps " LDL into the arterial intima. monocytes then migrate from the blood into the intima to become macrophages that pick up the lipid and transform into "foam cells". The macr -ophages take the LDL peroxidized by the endothelium, a process that involves free radicals (Steinbrecher, et al., 1984). This peroxidation mechanism can be prevented by antioxidants. This makes antioxidants a possible target for therapy of atherosclerosis (Bocan, et al., 1992). One of the reported antioxidants is melatonin. It is a hormone produced by the pineal body and its concentration in blood circulation decreases by aging (Ganong, 1990). The level of melatonin seems to play an important role in preventing the age dependent atherosclerosis through its antioxidant property (Richard, 1991). Melatonin administration was found to ameliorate athero-sclerotic changes in high cholesterol fed rabbits (Mattar et al., 2001).
Our present study is designed to investigate the possible action of melatonin on the changes recorded in experimental atherosclerosis in the rabbit aorta.

\section{Material and Methods}

\section{The animal:}

The New Zealand rabbit was the animal of choice because it is the most sensitive species for induction of atherosclerosis (Fennessy, et al., 1994 ). Thirty adult (about 12 weeks old) male rabbits were used throughout this investigation. The average body weight used was about $1.5 \mathrm{~kg}$

\section{Experimental groups:}

The animals were divided into three groups each of 10 animals.

Group I : ( Control group ):- Animals were raised on the ordinary diet alone ( without cholesterol or any antioxidants ) for 6 weeks.

Group II : ( Atherosclerotic group ):Animals were raised on the ordinary diet mixed with $1 \%$ cholesterol powder (Merck Company, Germany) for a period of 6 weeks (Fennessy , et al., 1994 )

GroupIII:(Melatonin-treated atheroscler otic group ):-

Animals were raised on cholesterolenriched diet. They were, also, drenchedby nasog -astric tube- $10 \mathrm{ml}$ saline solution containing $4.2 \mathrm{mg}$ Purified pharmaceutical grade of melatonin (Memphis Co. For Pharm.\&Chem. Ind. Cairo), dissolved in saline every night for 6 weeks. The total daily dose was calculated according to Paget \& Barnes(1964).

\section{Histological and histochemical Preparations}

The animals were dissected and the thoracic aorta was immediately excised, perfused by saline followed by neutral formol.

\section{A- Paraffin Sections :-}

Specimens were fixed in neutral buffered formol solution (Gretchen, 1979) for 48 hour, dehydrated, cleared and 
embedded in Paraffin. Thin $6 \mu \mathrm{m}$ sections representing control and treated specimens were mounted together on clean micros copic slides. The sections were then stained by the following stains:

1. Haematoxylin and eosin stain (Drury \& Wallington, 1980); for studying the general microscopic structure of the thoracic aortic wall.

2. Masson trichrome technique (Cook, 1974); used to differentiate the collagen fibers and the smooth muscle cells.

3. Modified Taenzer - Unna Orcein method (Unna, 1980) ; for studying the elastic fibers.

4. Periodic Acid Schiff technique (PAS)

( McManus, 1949) was used to study the glycosaminoglycans in the wall of thoracic aorta.

\section{B- Quantitative Analysis}

Stained sections were microscopically examined. Quantitation of the different par -ameters was performed by the computerized image analyses. The mean optical densities and areas were measured using Optimas 6.21(Media Cybernetics Inc.).

The statistical analysis was carried out according to the standard procedures and Student(t) test to estimate the significance of the difference between means using Microsoft Excell 2000.

\section{Results}

Changes in the microscopic structure compared to control, (plate $1 \mathrm{~A}$ ). Haematoxylin and eosin (H,E) stained sections of Atherosclerotic group (plate 1 B), show accumulation of amorphous material in some parts of tunica media(arrow head) that press the muscle and elastic fibers towards the intima. The intima shows some vacuolated areas (arrows), probably occupied by fatty material. Unlike the control, in which the covering endothelium is prominent (insert in A), Sections from Atherosclerotic group have a less conspicuous endothelium insert in B).

Melatonin treatment of atherosclerotic group (plate1 C) resulted in a better organized aortic structures than atheroscl erotic group. The endothelial lining (insert in C) is almost similar to control.

The thickness of the nuclear area of endothelium in the different groups is tabulated in table (1). Melatonin treated atherosclerotic animal aorta had endothelial cells with a mean thickness which was not statistically different from control. The mean thickness of endothelium of atherosclerotic group, however, was significantly lower than both control and melatonin treated. 

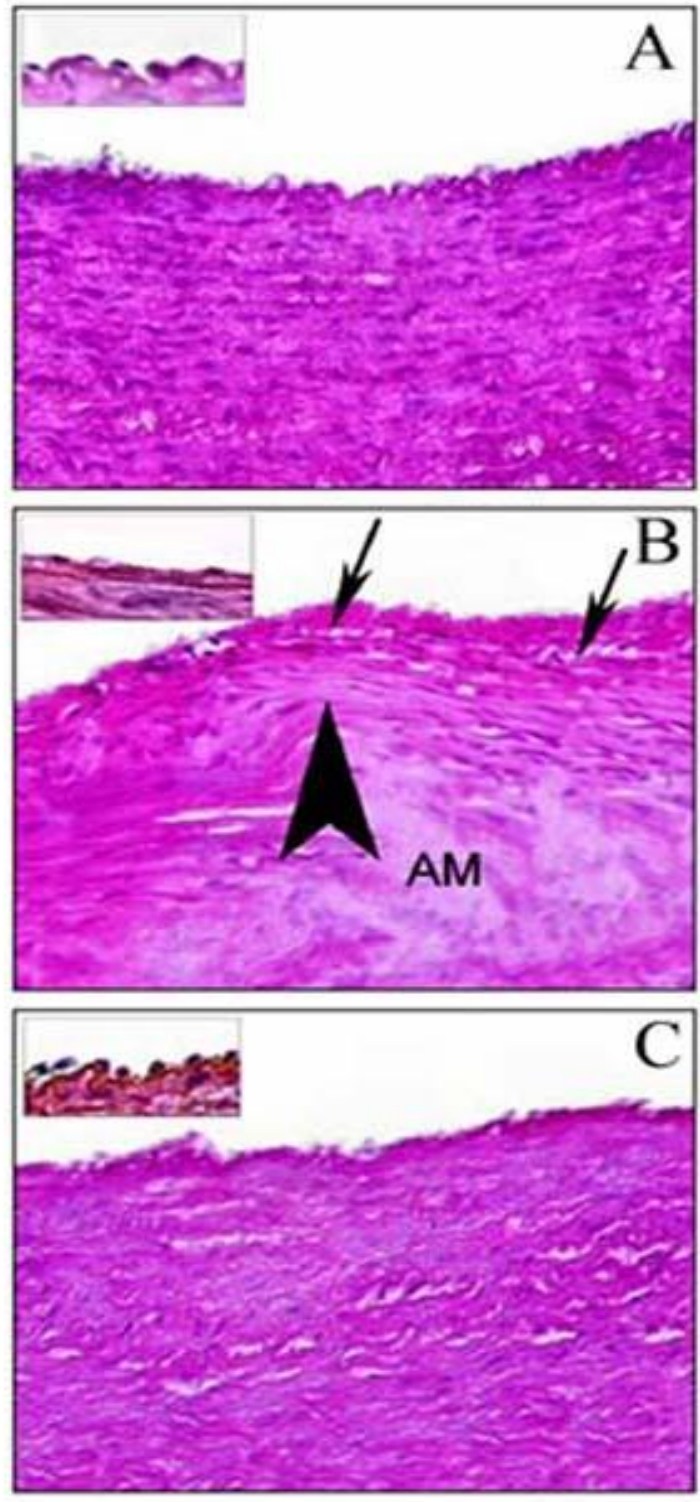

Plate I: Sections in the thoracic aorta of (A) control, (B) atherosclerotic and (C) melatonin treated atherosclerotic groups. The inserts are high magnification of the lining endothelium. Notice the denuded areas in the endothelial layer of atherosclerotic group The large head of arrow in (B) to the pressing on smooth muscles by amorphous material (AM). The small arrows point to the vaculated area in the subintima.( Hx,E: sections X200, insert X1000)

Table (1): Mean thickness of the nuclear region of endothelial cells of control and experimental animal arteries.

\begin{tabular}{|l|l|l|l|}
\hline & Control & Atherosc. & MelatoninTreated \\
\hline Mean & 9.33 & 7.42 & 8.68 \\
\hline STDEV & 2.38 & $1.7^{*}$ & $1.9^{\$}$ \\
\hline
\end{tabular}

The mean is significantly different from the mean obtained from control $(*)$ or atherosclerotic animals $(\$)$ when $(\mathrm{p} \leq 0.000001)$. 


\section{Mattar FE et al}

\section{Changes in the distribution of elastic fibers}

In orcein stained sections of atherosclerotic animals (plate II B), the pressing material, observed in the media of $\mathrm{H}, \mathrm{E}$ sections, resulted in discontinuity and diminution of

corrugation in elastic fibers. The internal elastic lamina was completely absent. The surface of the intima appeared denuded.
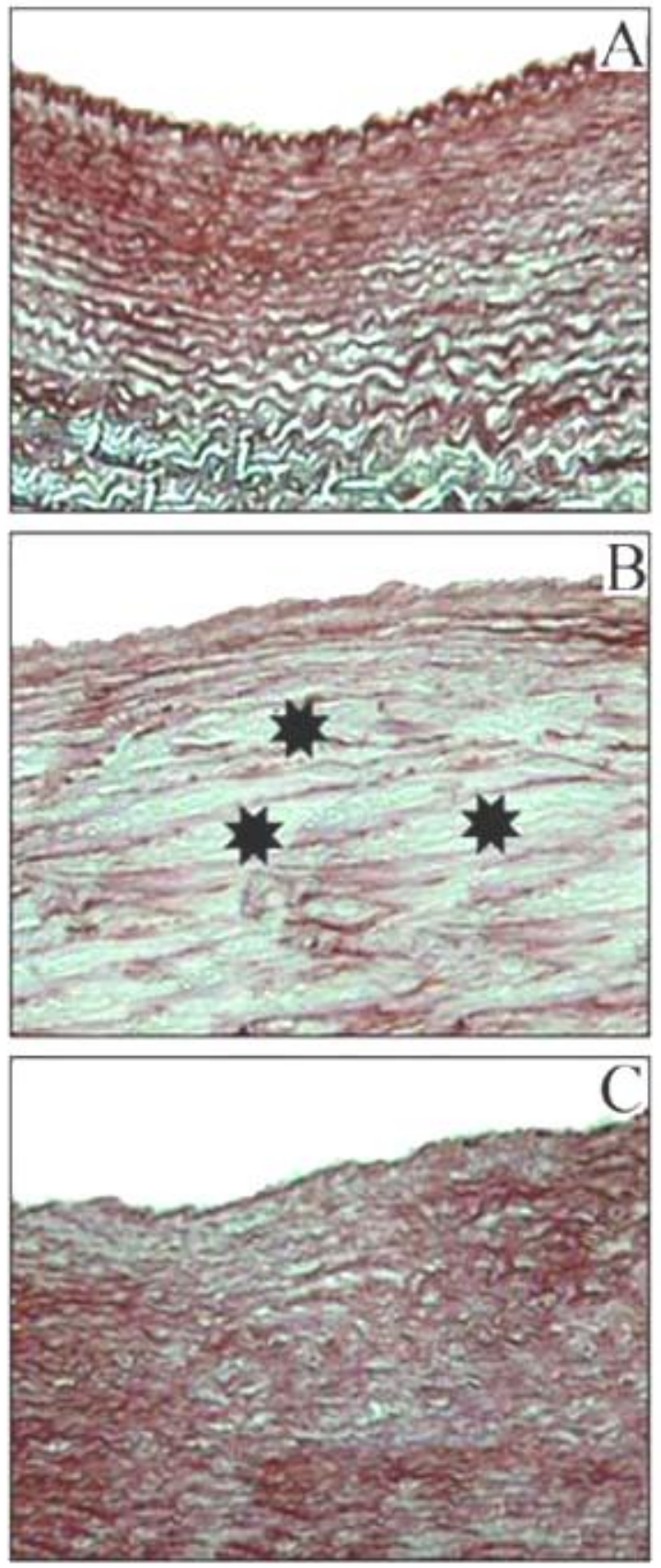

Plate II: Elastic fibers in the thoracic aorta of (A) control, (B) atherosclerotic and (C) melatonin treated rabbits. () areas devoid of fibers. ( Orcein stain X200). 
In melatonin treated atherosclerotic group (plate II C), The elastic fibers were much more abundant compared to atherosclerotic group. The fibers were, however, less packed and less corrugated and less organized compared with control. The internal elastic lamina was present but less organized than control.

The relative area occupied by the orcein stained elastic fibers was measured in the three groups (table 2). The area occupied by these fibers was highest in melatonin treated group followed by control and was the least in atherosclerotic group. The difference between the means was highly significant between atherosclerotic and both control and melatonin treated. However the level of significance was relatively lower between melatonin treated and control. The high value for melatonin treated is probably due to the distribution of non-packed fibers over a large area rather than increased fiber content.

Table (2) : Mean \pm standard deviation of the area occupied by elastic fibers in the intima and media of thoracic aorta of control and experimental animals.

\begin{tabular}{|l|l|l|l|}
\hline & Control & Atherosc. & $\begin{array}{l}\text { melatonin } \\
\text { treated }\end{array}$ \\
\hline Intima & $59.38 \pm 4.53$ & $44.81 \pm 7.56^{*}$ & $62.8 \pm 7.75^{*^{\$}}$ \\
\hline Media & $45.13 \pm 4.11$ & $32.83 \pm 7.87^{*}$ & $49.75 \pm 9.32^{\$}$ \\
\hline
\end{tabular}

The mean is significantly different from the mean obtained from control $(*)$ or atherosclerotic animals $(\$)$ when $(\mathrm{p} \leq 0.000001)$.

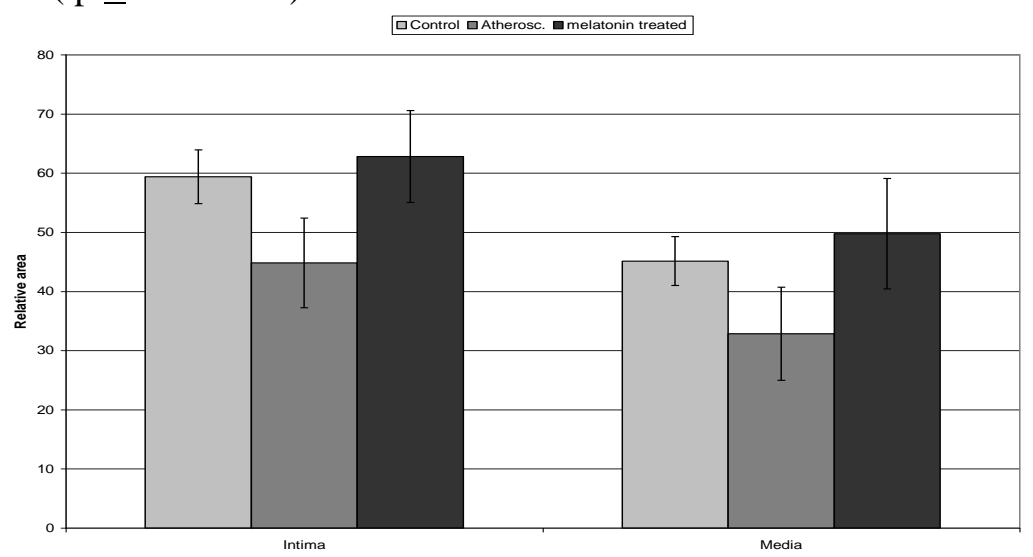

Figure(1) : Mean area occupied by elastic fibers in the intima and media of thoracic aorta of control and experimental animals.

\section{Changes in the distribution of collagen and smooth muscle fibers:}

In Masson trichrome stained sections, collagen stains green and muscle fibers stain red. In Atherosclerotic animal artery, the material of the media that interferes with the continuity and corrugation of the muscle and elastic fibers are stained green representing collagen ( plate III B ). 


\section{Mattar FE et al}

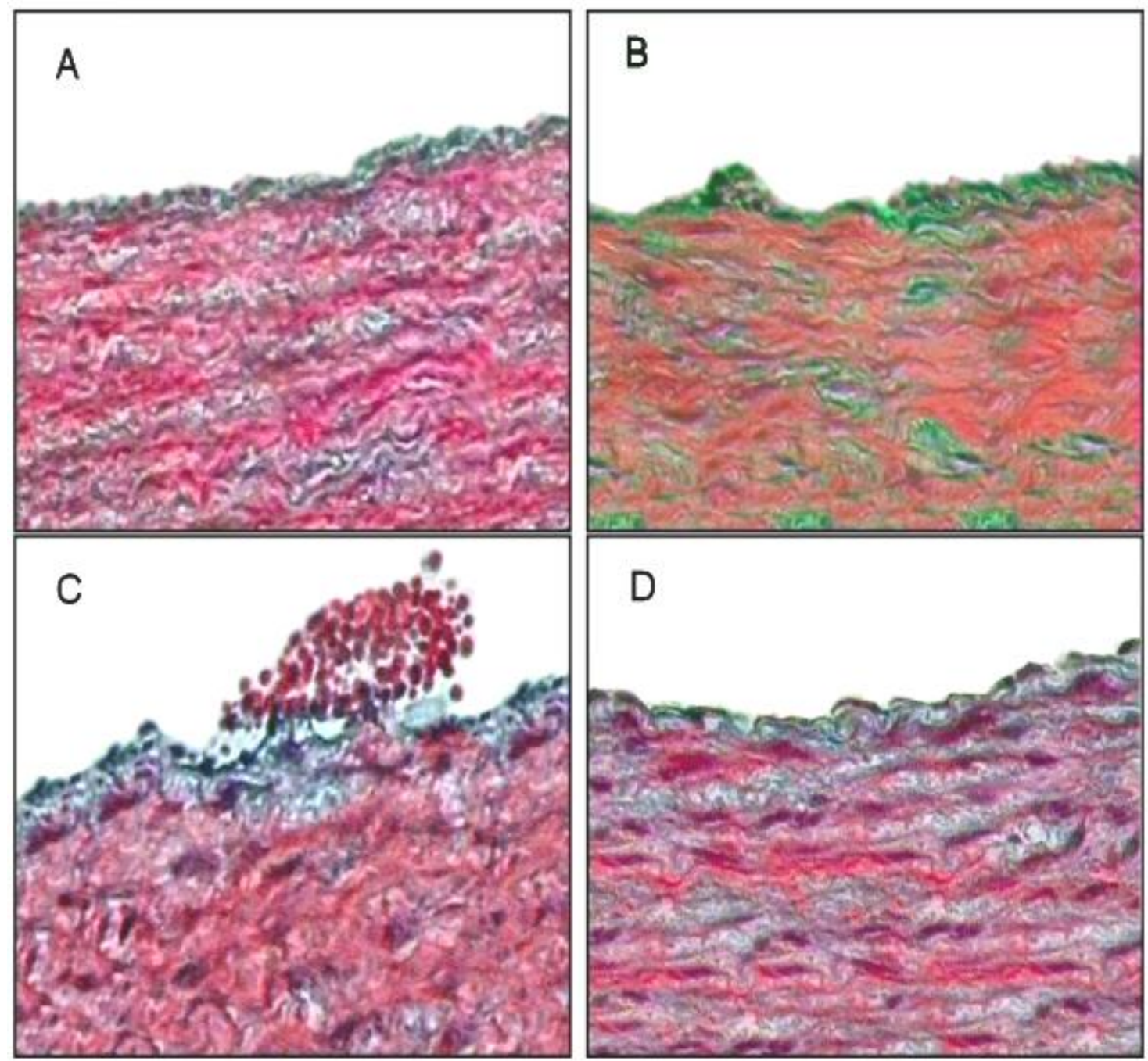

Plate III: Collagen (green) and smooth muscles (red) in the thoracic aorta of (A) control, (B), (C)atherosclerotic and (D) melatonin treated groups.. Notice the accumulation of blood elements on protruding endothelium of atherosclerotic aorta in C. ( Masson trichrome stain X400).

Collagen fibers and some smooth muscle elements were accumulated in the subintima. A blood clot was observed adhe -ring to the endothelial surface which bulged at the site of the thrombus (plate III C).

In sections from melatonin treated animal arteries, the collagen fibers interdigitated with the muscle fibers. The subintimal area occupied by collagen fibers, however, (plate III D) was less than atherosclerotic group (plate IIIB,C).

Measurement of the relative area occupied by collagen was recorded in table(4). The recorded area was high in atherosclerotic, intermediate in melatonin treated and low in control. The difference between the means was highly significant. On the other hand, 
the area occupied by smooth muscle fibers (table 5) was highest in control, intermediate in melatonin treated and lowest in atherosclerotic animal arteries. The means were significantly different.

Table (3) : Mean area occupied by collagen and smooth muscles in thoracic aorta of control and experimental animals.

\begin{tabular}{|l|l|l|l|}
\hline & Control & Atherosc. & Melatonin Treated \\
\hline Collagen & $29.54 \pm 11.8$ & $83.0 \pm 13.3 *$ & $59.37 \pm 11.35^{*} \$$ \\
\hline Muscles & $45.9 \pm 9.7$ & $31.73 \pm 9.17^{*}$ & $37.06 \pm 6.13^{*} \$$ \\
\hline
\end{tabular}

The mean is significantly different from the mean obtained from control $(*)$ or atherosclerotic animals $\left({ }^{\$}\right)$ when $(\mathrm{p} \leq 0.000001)$.

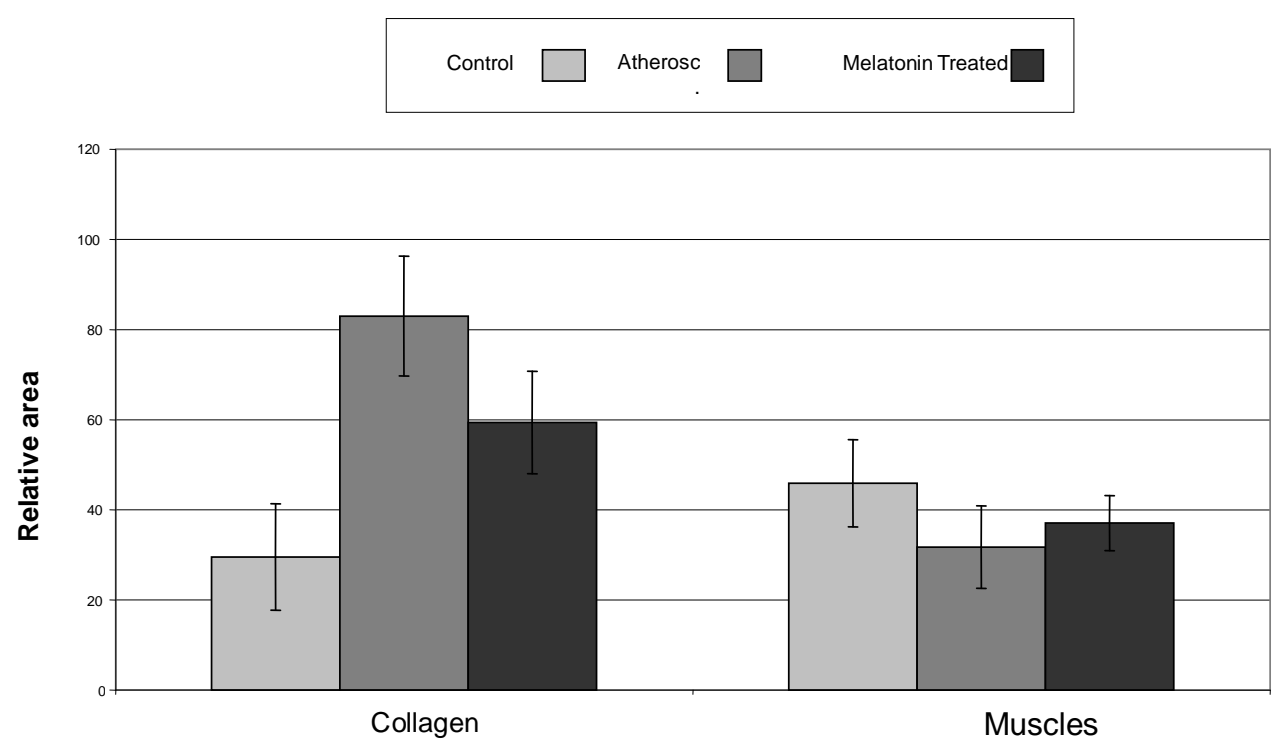

Figure (2) : Mean area occupied by collagen and smooth muscles in thoracic aorta of control and experimental animals.

The content and distribution of mucopoly-saccharides

The PAS positive material demonstrating glycosamino glycans were stained red (Plate IV). 


\section{Mattar FE et al}

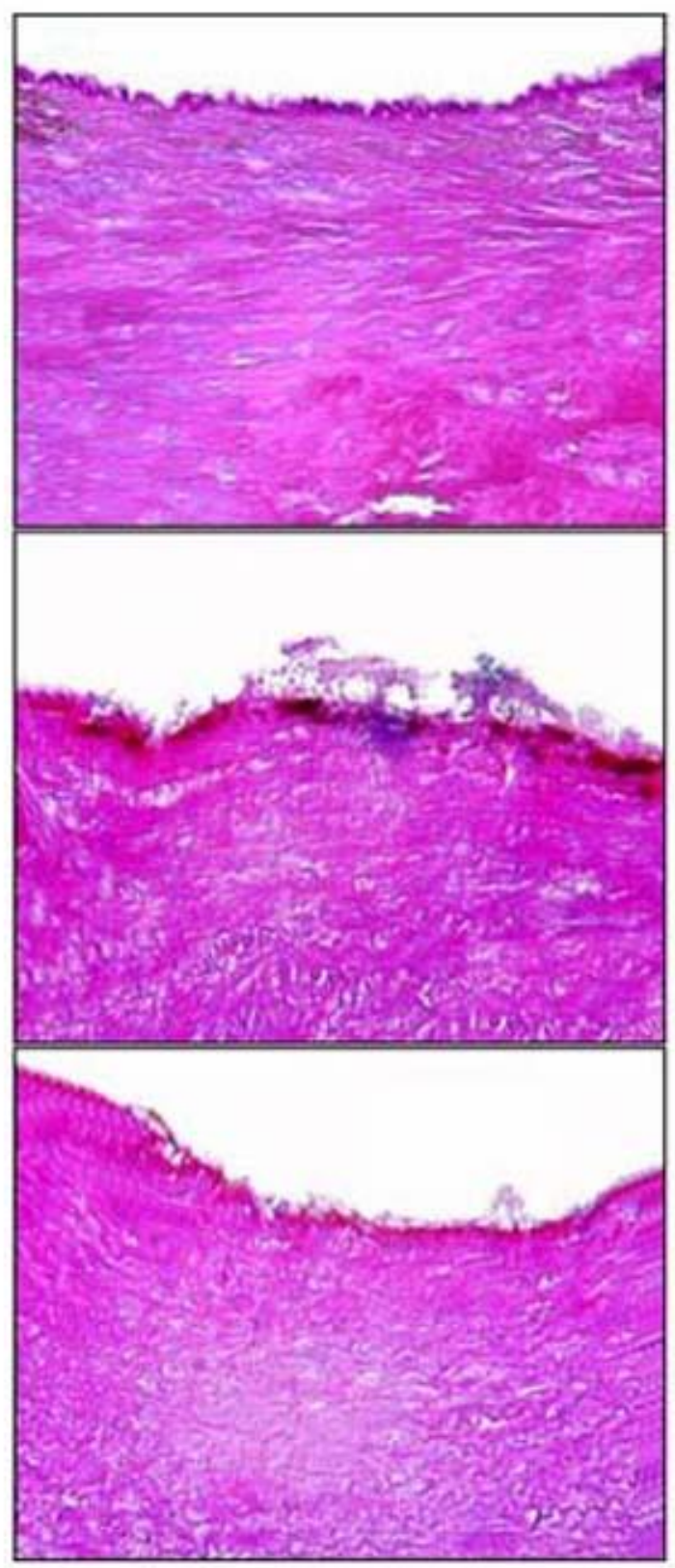

Plate IV: Glycosaminoglycans in the thoracic aorta of (A) control, (B)atherosclerotic and (C) melatonin treated groups.. Notice the dark staining subintima in (B) as well as accumulation of blood elements on protruding endothelium. ( PAS stain X200).

The stainability of the intima was much deeper in the aorta of atherosclerotic group ( IV,B), less evident in melatonin treated (IV,C) and least in control (IV,A). This was reflec -ted as significant difference between the mean optical density in the sub-intima of these groups (Table 5, figure 5). The quantitative data revealed that glycosamino glycan content of the media and adventitia followed the same trend as in the subintima (Table 5, figure 5). 
Table (4): Mean Optical density of PAS stained material in the three tunica of aorta from control and experimental animals.

\begin{tabular}{|l|l|l|l|}
\hline & Adventitia & Media & Sub-intima \\
\hline Control & $0.047 \pm 0.023$ & $0.045 \pm 0.017$ & $0.043 \pm 0.016$ \\
\hline Atherosclerotic & $0.115 \pm 0.018^{*}$ & $0.098 \pm 0.028^{*}$ & $0.105 \pm 0.038^{*}$ \\
\hline Melaton.treated & $0.074 \pm 0.03^{\$}$ & $0.064 \pm 0.02^{*}$ & $0.077 \pm 0.0 *^{\$}$ \\
\hline
\end{tabular}

The mean is significantly different from the mean obtained from control $(*)$ or atherosclerotic animals $\left({ }^{\$}\right)$ when $(\mathrm{p} \leq 0.000001)$

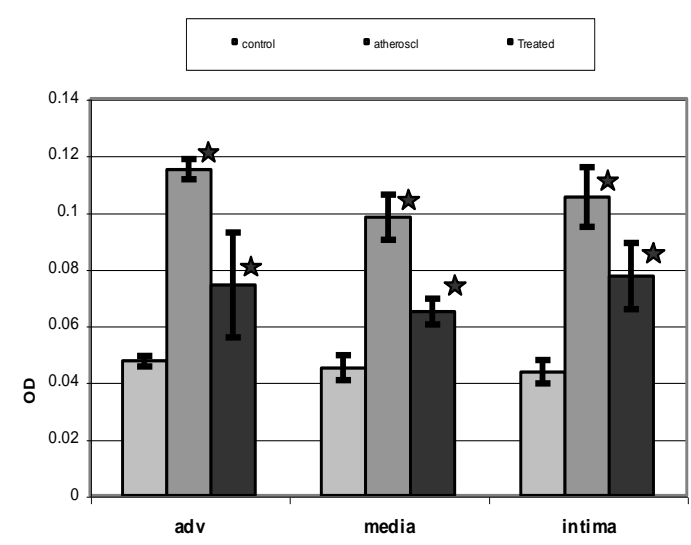

Figure (3): Mean Optical density of PAS stained material in the three tunicae of aorta from control and experimental animals.

\section{Discussion \& Conclusion}

Atherosclerosis is one of the most common diseases in the world. The exact etiology of the disease is still unknown. However, several theories have been proposed for the pathogenesis of atheros clerosis including the response to injury theory ( Steinberg \& Witztum, 1990), low density lipoprotein retention theory (Williams\&Tabas, 1995), and immunologyical hypothesis for atherosclerosis ( Hennig $\&$ Toborek , 2001). In all of these theories, it was suggested that lipid peroxidation has a primary effect on the onset of atherosclerosis (Berliner\& Heinecke , 1996; Chisolm, 1991; Navab, et al., 1995 ; Steinberg \& Lewis, 1997 ; Robert, et al., 1993 ).

Lipid peroxidation is produced by the effect of free radicals on lipids, especially circulating LDL (Goodman \& Gillman , 1990). Antioxidants, one of which is melatonin, are expected to exert a protective effect on atherosclerosis by prevention of lipid peroxidation ( Carr et $a l ., 2000)$. In this study, evaluation of the possible protective effect of melatonin in atherosclerosis was followed by evaluation of the changes in the components of arteries known to be affected by diet induced atherosclerosis.

The first component of the blood vessel involved in pathogenesis of atheros clerosis is the endothelial lining. Chronic and cumulative metabolic alterations of endothelium is induced by certain lipids, peroxidants, inflammatory cytokines ( Hennig \& Toborek 2001) and cell adhesion molecules (Mattar et al., 2001). In the present study, induction of atherosclerosis resulted in less prominent endothelial lining. Measurement of endothelial thickness showed a statist ically significant thinner endothelium in the vessels of induced atherosclerotic animals compared to control. This can be explained by inability of vascular endothelium to repair large areas of endothelial cell injury in atherosclerosis ( Reidy, et al.,1983). Smooth muscle cells of the underlying medial layer are capable of forming a thinner pseudoendothelium 
lining the luminal surface. Pseudoendothelial smooth muscle cell has an inhibitory influence on vascular endothelium regrowth (Campbell \& Campbell , 1986).

There was not any significant difference between endothelial cell thickness in control and melatonin treated groups. It seems, therefor, that melatonin which was reported as an antioxidant prevents the damage of endothelial cells by stabilization of their membrane and prevention of membrane lipid peroxidation (Berliner \& Heinecke, 1996; Chisolm, 1991; Navab et al., 1995 ; Steinberg \& Lewis , 1997; Robert et al., 1993).

The elastic fiber content in the intima and in the media of thoracic aorta was measured because atherosclerosis is a disease of intima and media. It was found that intimal and medial elastic fiber content decreased in atherosclerotic non treated group compared to control group. This can be explained by decreased elastin synthesis by smooth muscle cells ( Guideo \& Isabelle, 1996 ) as a result of oxidative damage of medial smooth muscle cells in atherosclerosis (Walter \& Israel ,1990).

The significant increase of intimal and medial elastic fiber content in melatonintreated compared to non treated group can be also due to the antioxidant effect of melatonin which protects smooth muscle cells in the media against the oxidative damage in atherosclerosis leading to increase of elastin synthesis ( Guido \& Isabelle, 1996).

Collagen content increased in atherosclerotic non treated group compared to control which can be explained by migration and proliferation of smooth muscle cells to the intima from the media leading to an increase in collagen synthesis. The collagen content of the media was not damaged (Leng-Peschlow \& StrengoHesse, 1991).

The collagen content of melatonin treated group was significantly less than non treated group which can be explained by antioxidant effect of melatonin which inhibits the fibrotic activity through significant reduction of the elevated serum level of P-III-P ( Procollagen III- peptide ), marker of fibrogenesis ( Leng - Peschlow \& Strenge - Hesse , 1991 ).

It was found that smooth muscle cell volume in the media decreased in atherosclerotic non treated group compared to control group which can be explained by free radical damage of smooth muscle cells in the media in atherosclerosis ( Reynolds et al., 1996).

The relative significant increase of smooth muscle cell volume in the media in melatonin treated group compared to non treated group can be explained by the antioxidant effect of melatonin which protects the smooth muscle cells against damage by free radicals.

Melatonin, as the case of other antioxidants, inhibits lipid peroxidation of cell membranc (membrane stabilizer ). Such inhibition may be through its action inside the cell by neutralizing and scavenging free radicals (Mattar and Moustafa,1996 ; Moustafaet et al. ,1995), or it may prevent the oxidative damage to the cell membrane through preventing the oxidation of polyunsaturated fatty acids (Reynolds, et al., 1996 ).

The amount of glycosaminoglycans in the matrix of non treated atherosclerotic aortic wall is significantly higher than control in all three tunica. Glycosaminoglycans are synthesized by smooth muscle cells. The intimal smooth muscle cells proliferation in non treated atherosclerotic group can explain the increased values in matrix of non treated atherosclerotic thoracic aortic wall ( Tatsuya et al., 1994). Melatonin treatment resulted in a value of glycosamino glycan in between the atherosclerotic and control values. Such differences is expected on the basis that melatonin improve the atherosclerosis related changes ( Robert, et al., 1993 ).

In conclusion, the present study suggests that melatonin administration ameliorates signs of atherosclerosis in high cholesterol-fed rabbits. Its effect may be due to its antioxidant action. However, it may also act as hormone supplement, since it was reported that decreased night-time level of melatonin were reported in patients 
with coronary artery disease (Sakotnik, et al., 1999).

Further studies are needed, however, to evaluate the effect of melatonin administration to atherosclerosis in human.

\section{References}

1. Berliner; J.A. and Heinecke ; J.W (1996): The role of oxidized lipoproteins in atherog -enesis. Free Rad. Biol. Med. 20;707-727.

2. Bocan; T.M.A.; Mueller, S.B., Brown E.Q.; Uhlendorf P.D., Mazur., M.J.and Newton, R.S. (1992): A ntiatherosclerotic effects of antioxidants are lesion specific when evaluated in hypercholesterolemic New Zealand white rabbits. Exp. Mol. Pathol. 57;70-83.

3. Campbell, J.H. and Campbell, G.R. ( 1986 ): Endothelial cell influences on vascular smooth muscle phenotype, Annu. Rev. Physiol., 48;295-300.

4. Carr, A.C., Mc Call, M.R., and Frei, B. (2000): Oxidation of LDL by myeloper oxidase and reactive nitrogen species; react -ion pathways and antioxidant protection. Arterioscler. Thromb. Vasc. Biol. ( United States), 20 (7): 1716-1723.

5. Chisolm, G.M. (1991): Oxidized lipoproteins and leukocyte - endothelial interactions: growing evidence for multiple mechanisms. Lab. Invest. 68:369-371.

6. Cook, H.C. (1974): Manual of histological demonstration techniques, Seventh Edition, Butterworths, London, 12-13.

7. Cormack, H. David (1997): Essential Histology, Eighth Edition, Lippincott Raven Publishers, Philadelphia, New York, U.S.A : 241-245.

8. Cormack, H. David (1987): Ham's Histology, Ninth Edition, J.B. Lippincott Company, Philadelphia, U.S.A :436-439.

9. Drury, R.A., Wallington E.A. (1980): Histological Techniques,5th Ed Oxford, N.Y., Toronto, Oxford University Press, U.S.A : 27-29.

10. Fennessy, Julie H., Campbell, Gordon R., Campbell (1994): Perindopril inhibits both the development of atherosclerosis in the cholesterol fed rabbit and lipoprotein binding to smooth muscle cells in culture. Atherosclerosis 106:29-41.

11. Ganong E. (1990): Review of Medical Physiology, Eleventh Edition, Middle East Edition, Lange Medical Public -ations, California, U.S.A :374-378.
12. Goodman S. Louis and Gilman Alfred (1990): The Pharmacological Basis of Therapeutics, Eighth Edition, Macmillan Publishing Company, Inc., New York, Collier Macmillan, Canada, LTD, Toronto, Bailliere Tindall, London :637-639.

13. Gretchen L.H. (1979): Animal tissue technique, $4^{\text {th }}$ edition W.H. Freeman and Company. San Francisco U.S.A :15-19.

14. Guido M. and Isabelle J. (1996): Cells, Tissues, and Disease: principles of general pathology. Printed in the U.S.A. Printed and bound by Braun- Brum field, Inc.:3033.

15. Hennig B., Toborek M. (2001): Nutrition and endothelial cell function: implications in atherosclerosis. Nutrition Research 21:279-293.

16. Leng - Peschlow E. and Strenge - Hesse A.Z. (1991): Atherosclerosis. Phytotherapie 12:162-167.

17. Mattar FE, Ismael AA, Kassem MA and Ibrahim KI (2001): Histochemical and immunohistochemical studies on the effect of melatonin on experimental atherosclerosis in the aorta of rabbit. The Egypt.J.Hosp.Med. 5:12-24.

18. Mattar, F.E., and Moustafa, S.A. (1996): " Possible role of membrane associated events in the effects of fat soluble antioxidants on carbohydrate metabolism in aged rat" J.Egypt.-Germ. Soc. Zool. 20:_67 $-78$.

19. Mc Manus. (1949): Staining Methods, Histologic and Histochemical , Seventh Edition, Acad. Press. London and New York :63-68.

20. Moustafa, S.A., Webster J.E., and Mattar F.E. (1995) : Effects of aging and antioxidants on glucose transport in rat adipocytes. Gerontology, experimental section. 41: 301 - 307

21. Navab, M., Fogelman A.M. and Berliner, J.A (1995): Pathogenesis of atheros clerosis. Am. J. Cardiol. 76: 18C-23C.

22. Paget, G.E.and Barnes J.M. (1964): Evaluation of drug activities and pharmacometrics toxicity test. Acad. Press. London and New York. Chap. 6: 135-139.

23. Reidy, M., Clowes, A. and Schwartz, S.M. (1983): Endothelial regeneration V. Inhibition of endothelial regrowth in arteries of rat and rabbit, Lab. Invest., 49:569-573.

24. Reynolds, James E.F., Martindale. (1996): "The Extra Pharmacopoeia. " 31 st. ed., Lange Medical Book, U.S.A : 13921395. 
25. Richard G. Cutler (1991): Antioxidants and aging. AM. J. Clin. Nutr., 53:373S379S.

26. Robert, K. Murray, Daryl K. Granner, Peter A. Mayes,and Victor W.Rodwell. (1993): Harper's Biochemistry, TwentyThird Edition, Middle East Edition. Lange Medical Book, U.S.A. : 129-131.

27. Sakotnik, A., Liebmann P.M., Stoschitzky K., Lerchen P., Schouenstein K., Klein W., Eber B. (1999): Decreased melatonin synthesis in patients with coronary artery disease. Eur. Heart J. Sep.; 20 (18): 1314-1317.

28. Steinberg D. (1983): Lipoproteins and atherosclerosis. A look back and a look ahead. Arteriosclerosis. 3:283-301.

29. Steinberg D., Lewis A. (1997): L Conner Memorial Lecture. Oxidative modification of LDL and atherogenesis. Circulation 95:1062-1071.

30. Steinberg D.and Witztum J.L. (1990): Lipoproteins and atherosclerosis: current concepts. J. Am. Med. Assoc. 264:30473052.
31. Steinbrecher, U.P., Parthasarathy, S., Leake D.S., Witztum, J.L., Steinberg D. (1984): Modification of low density lipoprotein by endothelial cells involves lipid peroxidation and degradation of low density lipoprotein phospholipids. Proc. Natl. Acad. Sci. U.S.A. 81:3883-3887.

32. Tatsuya, T., Masahiro M., Keiji S., and Tsuneo I. (1994): Novel monoclonal antibody (ASH 1A / $526 \mathrm{C}$ ) recognizing a sialo GM-2 developed on the surface of fatty streak of atherosclerotic aorta. Elsevier Science B.V. 30:255-259.

33. Unna, P. (1980): Carleton's Histological Technique, Fifth Edition, Oxford Medical Publications, Revised and Rewritten by R.A.B Drury and E.A. Wallington, 12:394397.

34. Walter Margaret, C.and Israel Hamilton, M.S. (1990): Principles of Pathology, Eleventh Edition, Churchill Livingstone, U.S.A :488-490.

35. Williams; K.j. and Tabas, I. (1995): The response to retention hypothesis of early atherosclerosis. Arterioscler. Thromb. Vasc. Biol. 15:551-561. 


\section{التقييم المجهرى الكمى لمعالجه تصلب الثرايين التجريبى

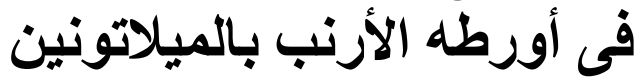

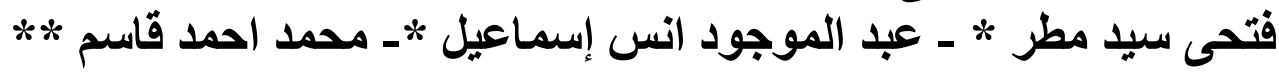

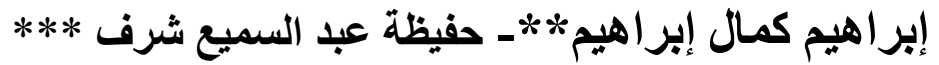

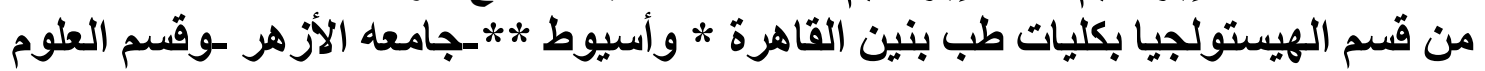

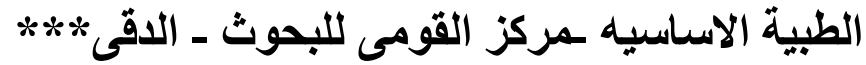

يعتبر تصلب الثرايين من الأمر اض الثائعة فى مصر ر و ولاتز ال أسبابه مجهولة , غير أن

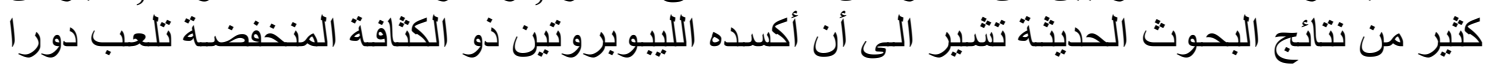

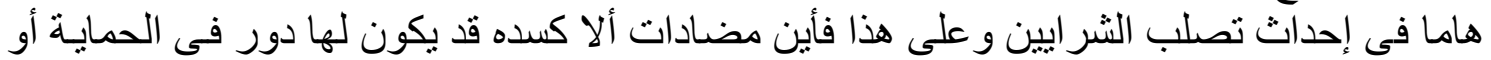

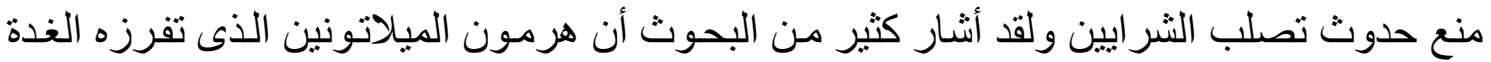

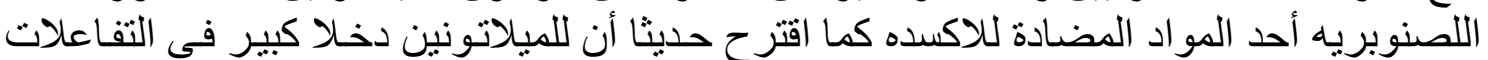

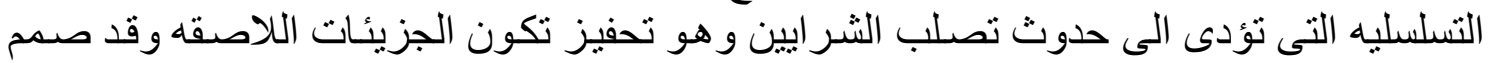

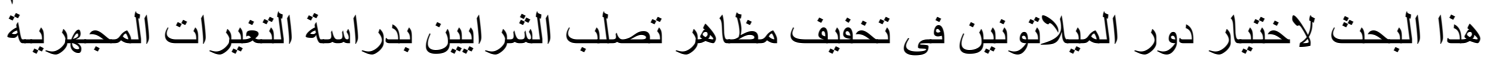

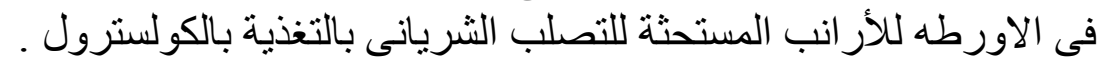

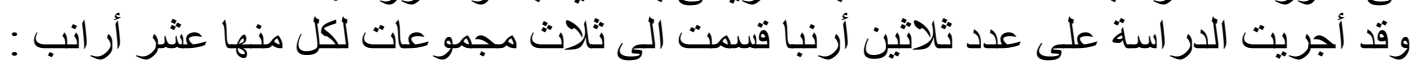

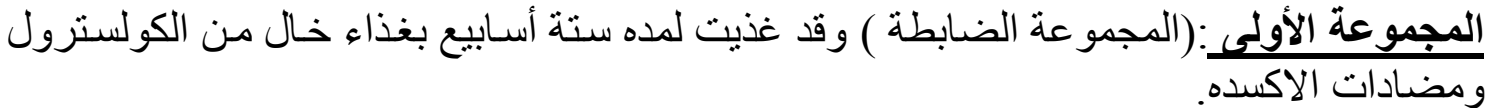
المجى كولسترول الثانية:مجمو عه تصلب الثـر ايين الغير معالجه ) وقد غذيت لنفس الددة بغذاء يحتوى

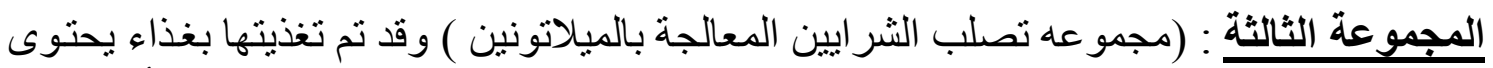

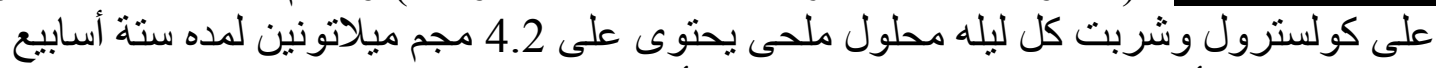

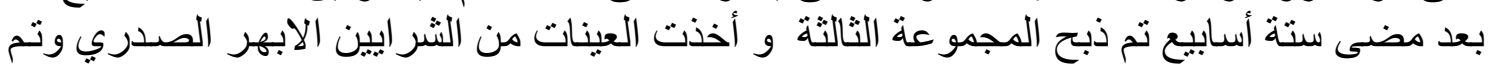

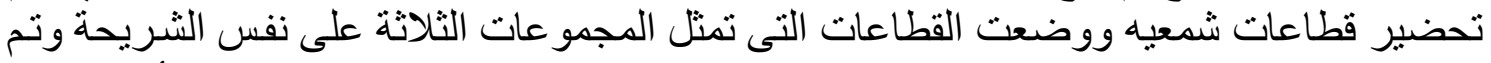

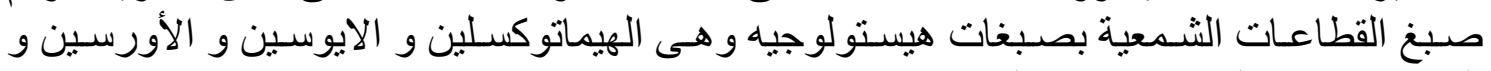

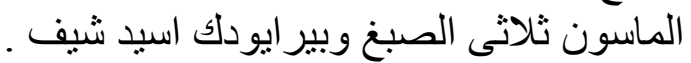

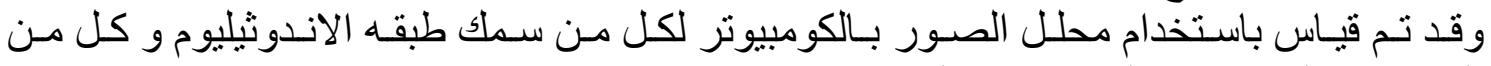

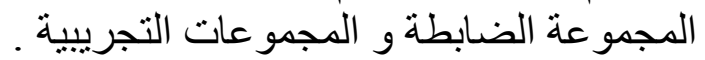

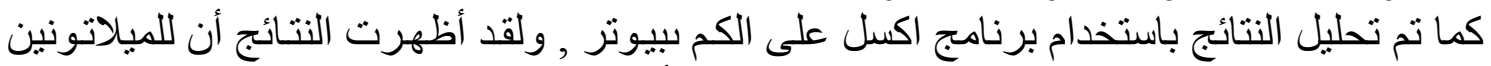

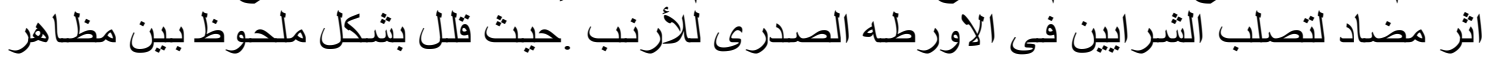

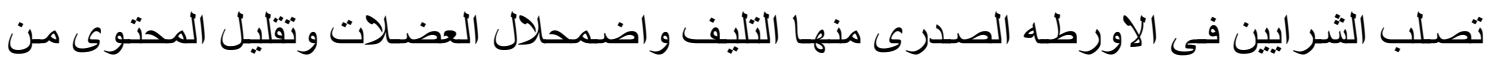

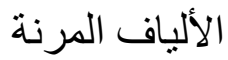
ويستتنج من هذا انـه قد يكون للميلاتونين أهميـه فى عـلاج تصلب الثر ايين بتقليل المضـاعفات

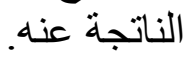

